\title{
A UTILIZAÇÃO DO EXTRATO DE BRASSICA OLERACEA VAR. CAPITATA F. RUBRA, COMO CORANTE ALIMENTÍCIO LÍQUIDO E EM PÓ
}

\author{
Emilly Adorno de Lima Vasconcelos ${ }^{1}$ e Maria de Fátima Mendes Paixão
}

1. Bolsista voluntario PIBIC/CNPq, Graduando em engenharia de Alimentos, Universidade Estadual de Feira de Santana, email: millyadorno95@gamil.com

2. Orientador, Departamento de Ciências Exatas, Universidade Estadual de Feira de Santana, e-mail: beltrano@provedor.br

PALAVRAS-CHAVE: Corantes Naturais; Antocianinas;Estabilidade.

\section{INTRODUÇÃO}

A adição de corantes aos alimentos visa restituir-lhes sua aparência original, que pode ser afetada durante as várias etapas de processamento (estocagem, embalagem ou distribuição), tornando-os visualmente mais atraente. Para colorir o alimento utilizam-se os corantes, quem podem pertencer a duas classes bem distintas, os sintéticos e os naturais. Os corantes sintéticos têm custo mais baixo e possuem maior estabilidade. Entretanto, o que se observa nos países desenvolvidos é que a quantidade de aditivos sintéticos permitidos vem diminuindo a cada ano em favor dos pigmentos naturais, que estão sendo mais utilizados (CONSTANT; STRINGHETA; SANDI, 2002).

A coloração na alimentação é um fator que além de atrair a atenção das pessoas para determinado alimento deve também associar benéficos à saúde, como proteção do organismo e prevenção de doenças. Por esse motivo, profissionais da área de saúde recomendam montar um prato com pelo menos cinco cores diferentes, pois bons resultados podem ser obtidos a partir da interação química entre alimentos de cores diferentes (ROCHA; REED, 2014).

As maiores vantagens dos corantes artificiais em alimentos são: estabilidade frente à luz, oxigênio, calor e pH; uniformidade na cor conferida; alto poder tintorial; isenção de contaminação microbiológica e custo de produção relativamente baixo. Porém a conscientização dos possíveis males à saúde faz com que os consumidores se preocupem com os efeitos gerados pelo uso de pigmentos sintéticos em produtos alimentícios e haja uma substituição por corantes naturais, que têm sido utilizados há anos sem evidências de danos à saúde. (CONSTANT; STRINGHETA; SANDI, 2002).

Os pigmentos objeto do nosso trabalho são as antocianinas, que são as principais responsáveis por inúmeras tonalidades de cores encontradas em flores, frutas e folhas. Em solução aquosa, as antocianinas são encontradas como uma mistura de diferentes estruturas químicas em equilíbrio: cátion flavilium (vermelho), base anidra quinoidal (azul), pseudobasecarbitol (incolor), e chalcona (incolor ou levemente amarela) (LOPES; Et al., 2007). 
As antocianinas têm sido usadas na coloração de alguns produtos, e, devido a sua variação de cor de acordo com o pH do meio, a preferência de seu uso tem se restringido para produtos ácidos. No entanto, apesar de largamente disseminadas na natureza, são poucas as fontes comercialmente utilizáveis de uso das antocianinas como corantes, embora tenham um amplo potencial colorante dentre os corantes hidrossolúveis (SCHIOZER; BARATA, 2007).

Diversos fatores interferem na estabilidade das antocianinas, portanto, a obtenção do pigmento deve ocorrer com o mínimo de alterações em suas características. A sensibilidade ao $\mathrm{pH}$ é o principal fator limitante no processamento, pois durante o processo pode haver variação do $\mathrm{pH}$ do meio, alterando a coloração desejada, afetando a cor e a estabilidade química quando utilizada como corante alimentício. Em soluções ácidas, a antocianina é vermelha, mas com o aumento do $\mathrm{pH}$ a intensidade de cor diminui. Em solução alcalina é verde e em alguns vegetais, como o repolho roxo (Brassica oleracea var. capitata f. rubra) é azul (LOPES; Et al., 2007). Observa-se que a estabilidade da antocianina é maior sob condições ácidas e Stringheta (1991) demonstrou que o aumento da quantidade de ácido tânico propiciou um acréscimo na estabilidade das antocianinas presentes, com uma redução significativa nos seus níveis de degradação (LOPES; Et al., 2007).

A temperatura é outro fator importante na estabilidade do corante a base de antocianinas, entretanto Lopes Et al (2007), relata que as antocianinas presentes no repolho roxo são as que apresentaram maior grau de estabilidade quando comparadas as outras. A excelente estabilidade das antocianinas do repolho roxo se deve às moléculas ricas em copigmentos que protegem o cátion flavilium do ataque nucleofílico da água. A presença de ácido caféico na molécula aumenta a estabilidade de antocianinas (FALCÃO; Et al, 2003). As antocianinas vêm sendo uma alternativa para a substituição gradativa dos corantes sintéticos, porém o seu uso é limitado pela instabilidade e por só poder ser usados em meio aquoso, seu uso se restringe a produtos como sorvetes, geleias, vinhos, entre outros (LOPES; Et al., 2007).

O presente estudo propôs a utilização de Repolho Roxo, como corante para uso domiciliar, sendo propostas duas formas de apresentação, a saber: como uma mistura líquida concentrada e outra em pó.

\section{MATERIAL E MÉTODOS}

A primeira etapa do trabalho foi um levantamento de informações sobre as antocianinas, sua estabilidade e uso como corante. A segunda etapa do trabalho foi desenvolvida no laboratório de Engenharia Bioquímica, do Departamento de Tecnologia, 
Labotec 2, no Laboratório 14, da Universidade Estadual de Feira de Santana (UEFS), BA, Brasil. O repolho in natura foi comprado em supermercados.

Para obtenção do extrato de repolho roxo utilizou-se um processador mixer, que tritura suas folhas, obtendo assim uma pasta, que é passada por uma peneira para separar o liquido do sólido, obtendo o extrato. $\mathrm{O}$ extrato obtido foi aquecido para evaporação da água, sem danos a coloração do corante. Para a forma do corante em pó, utilizou-se o corante concentrado, e a esse líquido foi adicionado o amido de milho, em uma proporção de 3:1, segundo a metodologia usada por Brito (2017).

Para testar o corante em pó e o extrato líquido concentrado foram usadas formulação de pratos em uma escala doméstica. Para obter a coloração avermelhada, foi adicionado ao extrato do repolho roxo algumas gotas do suco do limão, e, em seguida, utilizado o processo para obtenção do extrato em pó. Para obtenção da coloração azulada, adicionou-se ao extrato concentrado um pouco de bicarbonato de sódio e feito o processo para obtenção do extrato em pó. Assim como para a coloração roxa.

\section{RESULTADOS E DISCUSSÃO}

O repolho roxo (Brassicaoleracea var. capitata f. rubra) obtido por extração aquosa a quente é um ótimo indicador ácido-base, pois se o extrato for adicionado ao meio ácido ele irá adquirir uma coloração vermelha, e se estiver em meio básico a coloração é azul (como na figura 1). Neste estudo buscamos usar as três possibilidades de cores para utilizar o extrato aquoso como corante para alimento.

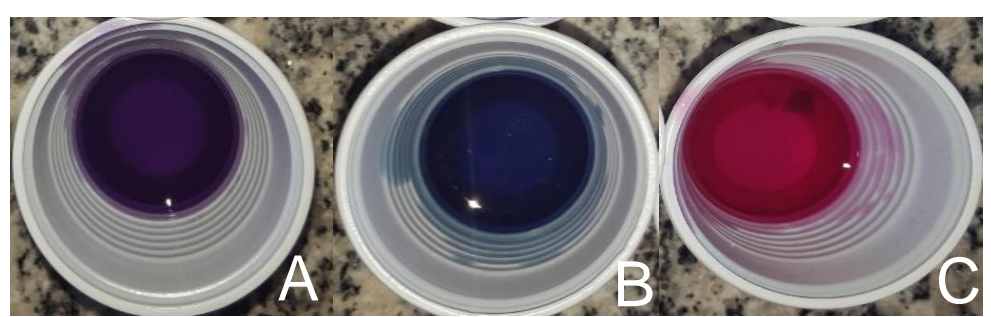

Figura 1: A- Extrato de repolho roxo em meio neutro; B- Extrato de repolho roxo em meio básico; C- Extrato de repolho roxo em meio ácido.

O extrato do repolho roxo in natura, foi obtido com o auxílio de um multiprocessador mixer, que produz uma pasta maciça de repolho roxo. Esta foi então peneirada e obteve-se um líquido com coloração mais intensa e melhor poder edulcorante. Em seguida, este líquido foi aquecido para evaporação da água e obtenção de uma mistura com maior concentração de pigmentos colorantes. A coloração vermelha e azul obtida a partir deste último formato foram bem mais fortes, porém gerou também um aroma intenso de folha verde, sem, contudo, 
comprometer seu uso como corante. O corante em pó obtido a partir do extrato líquido concentrado, deu os resultados expostos na Figura 2.

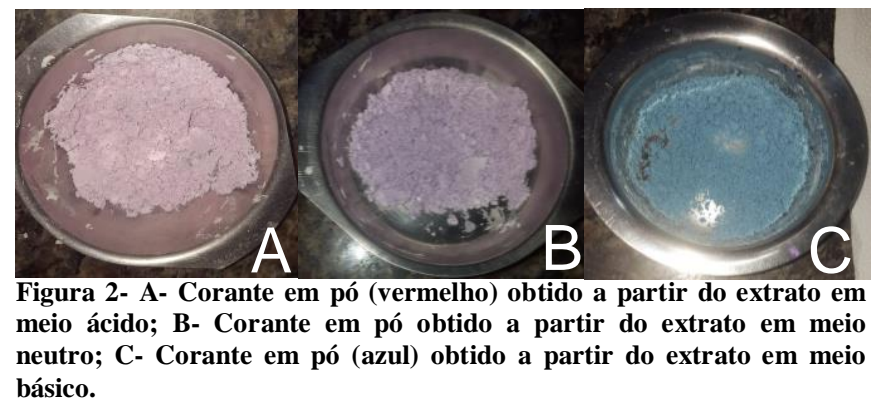

Foram realizados testes com os corantes, para uso domiciliar, em confeitos para bolos e doces. Inicialmente adicionou-se o corante ao coco seco, para ser utilizado como cobertura, em formato semelhante ao do granulado de chocolate (Figura 3). Segundo teste foi com a massa para beiju, que deu excelente resultado (Figura 3), e a temperatura utilizada para preparo do beiju não afetou o poder edulcorante da antocianina. O terceiro teste em alimento foi feito com mingau, utilizando o corante em pó do repolho roxo na cor desejada. O mingau feito com esse corante em pó, que é o amido de milho com pigmento. Obteve-se um mingau com a cor desejada e sem alteração no sabor do produto (Figura 3).

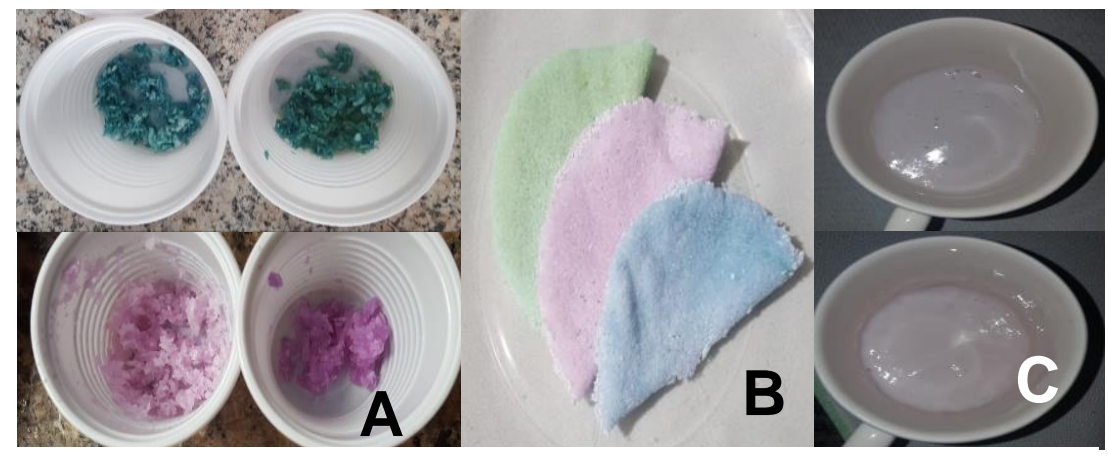

Figura 3- A- Coco seco com corante a base de repolho roxo; B- Beiju colorido com corante a base de repolho roxo; $\mathrm{C}$ - Mingau de amido de milho a base de corante de rebolho roxo.

\section{CONSIDERAÇÕES FINAIS}

O estudo propôs a utilização do repolho roxo como corante de alimentos para uso domiciliar. A obtenção do extrato aquoso concentrado e em pó permitiu alcançar resultados previstos pelo objetivo, sendo testados em beiju, mingau e coco seco ralado, sem alterar o sabor do alimento. Outros testes podem ser feitos utilizando o extrato seco, inclusive para identificar o tempo de vida, fator importante para sua conservação e uso em alimentos. O uso do liofilizador é uma alternativa para obtenção do extrato seco do repolho roxo, assim evitando a perda de coloração ocorrida pelo uso do amido para obtenção do corante em pó. 


\section{REFERÊNCIAS}

BRITO, A.; Faça seu Corante em pó alimentício. Disponível em <https://www.yo utube.com/watch?v=js-EUzAR69s> YouTube junho de 2017.Acessado em setembro de 2018. COnStAnT, P. B. L.; STRINGHETA, P. C.; SANDI, D.; Corantes Alimentícios. Disponível em: <https://revistas.ufpr.br/alimentos/article/view/1248/1048> Acesso em agosto de 2018.

EMBRRAPA.Pesquisa desenvolve corantes naturais de frutas tropicais com potencial funcional. Disponível <https://www.embrapa.br/busca-de-noticias/-/noticia/23670438/pesqui sa-desenvolve-corantes-naturais-de-frutas-tropicai s-com-potencial-funcional> Acesso em agosto de 2018

FALCÃO, L. D.; BARROS, D. M.; GAUCHE, C.; LUIZ, M. T. B.; Copigmentação Intra e Intermolecular de Antocianinas: uma revisão. Disponível em: <https://revistas.ufpr.br/alim entos/article/download/1170/971> Acesso em agos- to de 2018.

ROCHA, D. S.; REED, E.; Pigmentos Naturais em Alimentos e Sua Importância Para a Saúde. Disponível em <http://revistas.pucgoias.edu.br/index.php/estudos/article/viewFile/336 6/1953> Acesso em agosto de 2018.

ROSA, E. S.; Características nutricionais e fitoquímicas em diferentes preparações e apresentações de Hibiscus Sabdariffa L. (hibisco, vinagreira rosela, quiabo-de-angola, caruru-da-guiné) - Malvaceae. Disponível em <https://www.lume.ufrgs.br/bitstream/handle /10183/87222/000910449.pdf?sequence=1\&locale-attribute=es $>$ Acesso em agosto de 2018.

STRINGHETA, P.C.; Identificação da estrutura e estudo da estabilidade das antocianinas extraídas da inflorescência de capim gordura (Mellinisminutuflora, Pal de Beauv.), Campinas, 1991,138 p. Tese (Doutorado em Ciência e Tecnologia de Alimentos) UNICAMP.

SOARES, S. E.; Ácidos fenólicos como antioxidantes. Disponível em: <http://www.scielo. br/pdf/rn/v15n1/a08v15n1.pdf> Acesso em agosto de 2018.

Schiozer, A. L.; Barata, L. E. S.; Estabilidade de Corantes e Pigmentos de Origem Vegetal. Disponível em <www.revistafitos.far.fiocruz.br/index.php/revistafitos/article/downl oad/71/70> Acesso em agosto de 2018.

LOPES, T. J.; XAVIER, M. F.; QUADRI, M. G. N.;QUADRI, M. B; Antocianinas: Uma Breve Revisão Das Características Estruturais E Da Estabilidade. Disponível em <https:// periodicos.ufpel.edu.br/ojs2/index.php/CAST/article/viewFile/1375/1359>Acesso 08 de 2018. 